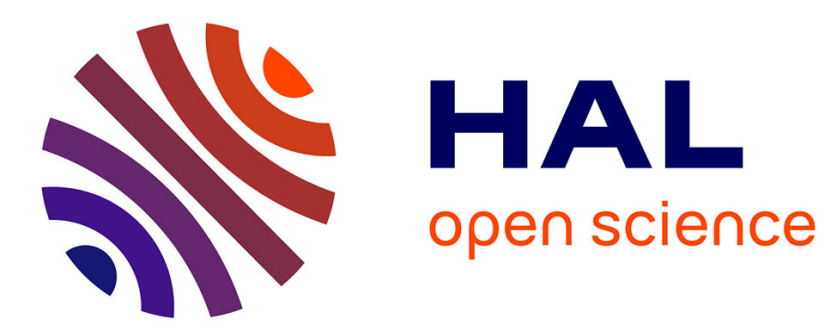

\title{
Wavelet-Based Optical Flow Estimation of Instant Surface Currents From Shore-Based and UAV Videos
}

Pierre Dérian, Rafael Almar

\section{To cite this version:}

Pierre Dérian, Rafael Almar. Wavelet-Based Optical Flow Estimation of Instant Surface Currents From Shore-Based and UAV Videos. IEEE Transactions on Geoscience and Remote Sensing, 2017, pp.1 - 8. 10.1109/TGRS.2017.2714202 . hal-01573715

\section{HAL Id: hal-01573715 \\ https://hal.science/hal-01573715}

Submitted on 10 Aug 2017

HAL is a multi-disciplinary open access archive for the deposit and dissemination of scientific research documents, whether they are published or not. The documents may come from teaching and research institutions in France or abroad, or from public or private research centers.
L'archive ouverte pluridisciplinaire HAL, est destinée au dépôt et à la diffusion de documents scientifiques de niveau recherche, publiés ou non, émanant des établissements d'enseignement et de recherche français ou étrangers, des laboratoires publics ou privés. 


\title{
Wavelet-based Optical Flow Estimation of Instant Surface Currents from Shore-based and UAV Video
}

\author{
Pierre Dérian and Rafael Almar
}

Preprint version, (c) (c) 2017 IEEE. Personal use of this material is permitted. Permission from IEEE must be obtained for all other uses, in any current or future media, including reprinting/republishing this material for advertising or promotional purposes, creating new collective works, for resale or redistribution to servers or lists, or reuse of any copyrighted component of this work in other works.

DOI: $10.1109 /$ TGRS.2017.2714202

\begin{abstract}
Instant fields of surface current are retrieved from shore-based and unmanned aerial vehicle videos by an optical flow (OF) method named "Typhoon". This computer vision algorithm estimates dense two-dimensional 2-component velocity fields from the observable motion of foam patterns in the surf zone. Despite challenging image data resolution and quality, comparison of $\mathrm{OF}$ surface current estimates with measurements by an acoustic Doppler velocimeter reveals its ability to capture both wave-to-wave fluctuations and low-frequency variations. The method is also successfully applied to the monitoring of a "flash rip" event. Our study shows clearly the high potential of this method in the nearshore, where the rapid development of webcams and drones offers a large amount of applications for swimming and surfing safety, engineering and naval security and research purpose, by providing quantitative information.
\end{abstract}

Index Terms-Remote sensing, Sea surface, Sea coast, Image motion analysis, Geophysical inverse problems, Wavelet transforms, Unmanned aerial vehicles, Rip currents.

\section{INTRODUCTION}

$\mathbf{T}$ HE observation of the nearshore circulation is essential for many aspects. For example, rip currents are the main cause of drowning of swimmers at many beaches around the world. Currents are also crucial for quantifying sediment transport, in particular longshore drift and transient exchanges between surf zone and outer part. Since the mooring of instruments is rather costly and unsafe in such energetic environments, remote sensing techniques have emerged to estimate surface current structure and velocity: marine radars relying on the backscattered signal from rough surface [1] as well as video-based systems have been developed for over twenty

Manuscript received XXXX, 2016; revised YYYY; accepted ZZZZ. This study was funded by French grants through ANR (COASTVAR: ANR-14ASTR-0019) and INSU (LEFE and EC2CO programs), and the UNESCO co-chair ICPMA/IRHOB.

Mr. Dérian is with the Fluminance team of Inria Rennes - Bretagne Atlantique, France (email: pierre.derian@inria.fr).

Mr. Almar is with the ECOLA team of LEGOS (CNRS / IRD / CNES / Université de Toulouse, France) (email: rafael.almar@ird.fr). years [2]. A few studies were dedicated to the estimation of current along one dimension [3], [4]. For two-dimensional (2D) measures, most approaches rely on cross-correlation (CC) methods [5], [6], although alternative tracking methods exist [7]. Particle image velocimetry (PIV) [8], also based on CC, is preferred for laboratory experiments where high temporal and spatial resolutions can be achieved [9], [10]. Classical PIV (or CC) methods are particularly interesting when applied to isolated zones but may become computationally intense when wide fields are considered. As formerly suggested by [5], related but alternative methods based on dense optical flow (OF) $[11]$ are promising.

Recent advances in optical sensors enable to apply such methods to unmanned aerial vehicles (UAVs) [12] and permanent camera images. Although UAVs suffer from relatively short flight times, they offer wide fields of view and thus complement conventional measurements by visualizing the spatial structures of wave-by-wave current (e.g., orbital velocities or swash flow within a cusp) or transient circulations (e.g., rip pulsations and shear waves). Permanent cameras appear better suited to the study of day-to-day or longer-term dynamics (e.g., longshore current), such as storm erosion-recovery cycles and seasonal evolution. These data complete nicely wavedissipation patterns and bathymetry or topography estimates, in particular in connection with the development of dataassimilation methods in three-dimensional numerical models [13], with a former attempt to include radar-based currents by [14].

The overall aim of the present study is to test an OF algorithm named Typhoon, formerly applied to aerosol lidar images for wind estimation [11], to recover two-component and 2D surface currents from videos recorded at Grand Popo, Benin (Gulf of Guinea, West Africa). After briefly introducing the method, its potential is first assessed through a comparison with a high-frequency acoustic Doppler velocimeter (ADV), then by the monitoring of a "flash rip" event highlighted by a dye release.

\section{THE TYPHOON ALGORITHM}

The Typhoon algorithm belongs to the family of dense OF estimators. Such methods feature two major differences with respect to the CC-based approaches. First, they rely on a global formulation: the entire vector flow field is estimated simultaneously by solving a single problem. Second, they 
provide a dense vector field, that is to say one vector at every pixel of the input image. CC vector fields, on the opposite, are estimated by solving as many independent problems as vectors in the field. And, from the size of interrogation windows, $\mathrm{CC}$ fields are usually sparser than input images. The Typhoon software has been previously validated on synthetic and actual PIV data, and more recently on aerosol lidar imagery for wind measurement in the lower atmosphere [11]. This section gives a rapid overview on the algorithm; details on the mathematical developments and implementation as well as earlier validations can be found in [15], [16].

Let $I_{n}(\mathbf{x}) \triangleq I\left(\mathbf{x}, t_{n}\right)$ be the image intensity at pixel $\mathbf{x}$ and discrete time $t_{n}$. The OF algorithm estimates the 2D 2component apparent displacement field $\mathbf{u}(\mathbf{x})$ at every pixel $\mathbf{x}$ of input images. This displacement is measured in pixel (px). When image resolution $\delta_{x} \mathrm{~m} / \mathrm{px}$ and acquisition time-step $\delta_{t} \mathrm{~s}$ are available, an estimate of the instantaneous velocity $\mathbf{v}(\mathbf{x})$ is given by

$$
\mathbf{v}(\mathbf{x})=\frac{\delta_{x}}{\delta_{t}} \mathbf{u}(\mathbf{x})
$$

The entire displacement field $\mathbf{u}$ is estimated by minimizing a functional defined over the image domain $\Omega$ :

$$
\begin{aligned}
\mathbf{u}=\arg \min _{\mathbf{u}} & \left\{\frac{1}{2} \int_{\Omega}\left[f_{\text {data }}(I, \mathbf{u})\right]^{2} d \mathbf{x}\right. \\
& \left.+\frac{\alpha}{2} \int_{\Omega}\left[f_{\text {reg }}(\mathbf{u})\right]^{2} d \mathbf{x}\right\} .
\end{aligned}
$$

$f_{\text {data }}$ is the data model that connects input images $I$ to the unknown displacement $\mathbf{u}$. The regularization $f_{\text {reg }}$ depends on $\mathbf{u}$ only. The parameter $\alpha>0$ balances the two terms and is fixed by the user.

The data model used in Typhoon is the "displaced frame difference" (DFD):

$$
I_{n+1}\left(\mathbf{x}+\mathbf{u}\left(\mathbf{x}, t_{n}\right)\right)=I_{n}(\mathbf{x}) .
$$

This model assumes the consistency of image intensity along the trajectory of tracers during the time interval $\left[t_{n} ; t_{n+1}\right]$. In the context of surface current estimation, this assumption is challenged by the large displacements and important visual deformations of foam patterns that occur when waves roll over the surf zone. The scene illumination is also subject to rapid changes e.g. from cloud shadows. Thus, it is important to note that from formulation (2), the data model is not strictly enforced. Instead, the solution achieves a balance between trying to follow the model on one hand and the regularization on the other, giving more weight to either one of these two terms according to the $\alpha$ parameter.

Regularization schemes often encourage the estimate $\mathbf{u}$ to follow some smoothness assumption. This work uses the simplest first-order regularization, originally introduced in [17], which penalizes strong velocity gradients. For each displacement component $u_{i}, i=1,2$ :

$$
f_{r e g}\left(u_{i}\right)=\left|\nabla u_{i}\right|=\sqrt{\left(\frac{\partial u_{i}}{\partial x_{1}}\right)^{2}+\left(\frac{\partial u_{i}}{\partial x_{2}}\right)^{2}} .
$$

The regularizer also takes precedence over the data model locally where the latter is inefficient. Typically, this happens within uniform regions of the input images, e.g. off the surf zone where little to no foam features are observed.

The DFD model (3) and the Horn and Schunck regularizer (4) inserted into (2) complete the motion estimation problem:

$$
\begin{aligned}
\mathbf{u}\left(t_{n}\right)=\arg \min _{\mathbf{u}}\{ & \frac{1}{2} \int_{\Omega}\left[I_{n+1}\left(\mathbf{x}+\mathbf{u}\left(\mathbf{x}, t_{n}\right)\right)-I_{n}(\mathbf{x})\right]^{2} d \mathbf{x} \\
& \left.+\frac{\alpha}{2} \int_{\Omega} \sum_{i=1,2}\left|\nabla u_{i}\left(\mathbf{x}, t_{n}\right)\right|^{2} d \mathbf{x}\right\} .
\end{aligned}
$$

The DFD model (3) is not linear in $\mathbf{u}$, so that the whole functional (5) is not quadratic. To ensure a successful minimization, optical flow methods often rely on an incremental multiresolution strategy. The largest displacements are estimated first on a coarse version of input images, and then the flow field is iteratively refined as the algorithm progresses towards finer scales. In Typhoon, this "coarse-to-fine" estimation is handled with the help of wavelets.

Wavelet bases offer multi-resolution (or equivalently, multiscale) representations of signals [18]. Here, each motion component $u_{i}$ is expressed as the inverse transform of (i.e. reconstruction from) its corresponding multi-scale wavelet coefficients $c_{i}$ :

$$
u_{i}=W_{i n v}\left(c_{i}\right), \quad i=1,2,
$$

where $W_{\text {inv }}$ denotes here the inverse wavelet transform. The set of wavelet coefficients $\left\{c_{1}, c_{2}\right\}$ hence becomes the unknown to the estimation problem. Coarse-scale coefficients are estimated first, then finer-scale details are successively added. The wavelet representation thus enables a "natural" coarse-tofine estimation [15]. Furthermore, regularization schemes such as (4) find a relatively simple yet very accurate implementation in the wavelet framework [16].

The algorithm is implemented in $\mathrm{C}++$ with a GPUacceleration in NVIDIA CUDA 11 An online interface ${ }^{2}$ to a $\mathrm{CPU}$-only version is available for testing purposes.

\section{SITE AND DATA}

The Bight of Benin (Fig. 1.b) is a sandy open wavedominated microtidal environment exposed to long-period swells coming from high latitudes in the South Atlantic (ECMWF Era-interim reanalysis 1979-2013 annual deep water wave averages: $H_{s}=1.36 \mathrm{~m}, T_{p}=9.4 \mathrm{~s}$, Dir $=\mathrm{S}-\mathrm{SW}$, see [19]). This stretch of coast presents a longshore-uniform low tide terrace and a steep upper shoreface (Fig. 1]a). Yearround oblique long swells [20] drive an important eastward littoral drift of 0.8 to $1.5 \times 10^{6} \mathrm{~m}^{3} / \mathrm{yr}$ [21], [22], together with frequent flash rips (dangerous offshore-oriented transient currents, [23]).

A field experiment was conducted at Grand Popo beach $\left(6.2^{\circ} \mathrm{N}, 1.7^{\circ} \mathrm{E}\right.$, Fig. 11a) from 10 to 18 March 2014 [24]. A Nortek ADV was deployed in the swash zone during daylight hours (Fig. 11d). Every day, various drifter releases were conducted in the surf zone around mid-tide to determine

${ }^{1}$ Compute Unified Device Architecture.

2 http://allgo.inria.fr/app/typhoon 
longshore current variability [23]. Tide varied from neap to spring tidal ranges during the experiment, from $0.3 \mathrm{~m}$ to $1.2 \mathrm{~m}$ respectively. Waves were energetic and relatively long (1.2 $\mathrm{m}<H_{s}<1.6 \mathrm{~m}$ and $T_{p}=10-12 \mathrm{~s}$ ), with initial higher waves (up to $1.8 \mathrm{~m}$ ), coming from south-west, generating consistent eastward longshore currents. Surf zone longshore current varied from $0.4 \mathrm{~m} / \mathrm{s}$ to $0.8 \mathrm{~m} / \mathrm{s}$, inner shelf current from 0.05 to $0.3 \mathrm{~m} / \mathrm{s}$, and swash current from 0 to $0.5 \mathrm{~m} / \mathrm{s}$.

A long-term video camera VIVOTEK IP7361 (Fig. 1 c) was deployed in February 2013 [24] on a 15-m high semaphore belonging to the Navy of the Republic of Benin, 80-m distant from the shore (which is the approximate beach width). During the experiment, $2 \mathrm{~Hz}$ videos were recorded at $1600 \times 728 \mathrm{px}$; a sample frame is shown Fig. 1 a. Rectification of images from pixel to real world coordinates was accomplished by direct linear transformation using GPS ground control points [25] after a correction for the lens radial distortion [26]. Although varying somewhat throughout the field of view, the pixel footprint was on the order of 0.25 and $0.05 \mathrm{~m}$ in the region of interest (surf zone of the instrumented zone) for the crossshore and alongshore directions, respectively.

Additionally, dye releases of different colors were conducted in the surf zone at mid-tide (Fig. 1.e) to monitor the dispersion induced by flash rips [23]. This was coupled with UAV flights (STB DS6 hexacopter) at an elevation of $100 \mathrm{~m}$ (Fig. 1.f). The UAV camera (NIKON D700) was looking down, with a vertical angle, and recorded $4256 \times 2832$ px scenes at $1 \mathrm{~Hz}$. No proper rectification was possible with this data set, but the image sequence was nonetheless compensated for the UAV motion after acquisition. Some remaining camera motion can still be noticed over the entire 293-frame sequence, but the frame-to-frame camera motion is sufficiently negligible to apply OF. Without rectification, this UAV data set will help to qualitatively assess the ability of the OF estimates to reproduce the flow behavior observed through the dye.

\section{RESULTS}

\section{A. Pre-processing: reducing the influence of propagating} rollers

As with most video methods, a robust pre-processing of the raw data is essential. First, color images (red, green, blue channels - RGB) are converted to grayscale. The shore images were processed with an usual luminance formula: $I=0.2125 R+0.7154 G+0.0721 B$. Regarding the UAV data, this is achieved by keeping the blue channel only $(I=B)$, as the blue dye that was released does not show up in this channel. This way, the additional information brought by the dye motion is not used by the estimator, but rather serves as a qualitative reference. Then, when estimating surface current, the challenge is to separate wave-breaking rollers, which propagate at phase speed, from remaining currents. As shown previously by [27] breaking bores have a signature rather correlated alongshore. This can be removed by applying a radial filtering in the polar space using the Radon transform [4]. A high-pass 2D median filter was preferred in this work, being less computationally intensive than the Radon filter and yielding comparable results. The high-pass median filter removes the largest structures (cloud shadows, sand bars, rollers) and improves the visualization of the residual smallscale patterns. Fig. 2 presents the color input images as well as the grayscale median-filtered output for the shore and UAV data.

\section{B. Wave-by-wave currents: comparison with an acoustic Doppler velocimeter}

The OF is applied to a $60 \times 60 \mathrm{~m}$ area (at $0.1 \mathrm{~m} / \mathrm{px}$ image resolution) located in the surf zone around the ADV (Fig. 1 1 a), over a 4.5-hour window ( $\approx 32000$ video frames). Instantaneous fields retrieved by Typhoon are spatially averaged, over a disk of radius $1 \mathrm{~m}$ located next to the ADV, in order to obtain time-series to be compared with the ADV measures. Neither OF nor ADV measures are controlled for outliers. A video illustrating this setup is provided as additional material at http://ieeexplore.ieee.org. It was found after the field campaign that the camera acquisition time-step fluctuated around the theoretical $0.5 \mathrm{~s}$, with $12.5 \%$ time-steps between $0.85 \mathrm{~s}$ and $0.95 \mathrm{~s}$ - nearly twice the expected value. Therefore, both $\mathrm{ADV}$ and $\mathrm{OF}$ time-series are resampled from $8 \mathrm{~Hz}$ and $\approx 2 \mathrm{~Hz}$, respectively, down to $0.5 \mathrm{~Hz}$ by averaging values within each 2-s bin.

Figures 3 and 4 present measures obtained for the crossand alongshore velocity components, respectively, in terms of wave-to-wave fluctuations $u, v$ (resampled $0.5-\mathrm{Hz}$ signal) and slow variations $\bar{u}, \bar{v}$ (2-min rolling mean). Both components feature low-frequency oscillations (Fig. 3 and 4 , top) induced by groupiness, infragravity or shear waves [23], [28]. Passing waves with an oblique angle $\left(H_{s}=1.1 \mathrm{~m}, T_{p}=11 \mathrm{~s}\right.$, Dir $=10^{\circ}$, see [28]) are the dominant signal in the $0.5 \mathrm{~Hz}$ cross-shore component (Fig. 3 , bottom). For this component the instantaneous measures $u$ appear to be in good agreement, while the slow variations $\bar{u}$ seem hardly comparable. This last observation can be explained by the sheared vertical profile of the cross-shore component. The OF estimates the apparent surface current and shows a net onshore flux $(\bar{u}>0)$, while the ADV provides a measurement at $0.2-0.3 \mathrm{~m}$ under the surface (over a total depth of $\approx 1 \mathrm{~m}$ ) where the average flux is already weaker. Significant differences between OF and ADV measures can therefore be expected in the crossshore direction. Regarding the alongshore component (Fig. 4), the slow variations $\bar{v}$ match well between OF and the ADV, while the instantaneous measures are less in agreement. Here, a possible explanation is that the important visual deformation of the foam patterns due to the passing waves, well captured in the cross-shore component $u$, considerably affect the accurate OF estimation of the instantaneous alongshore displacement $v$.

The statistics of Table I confirm the prior observations from the time-series, with correlation coefficient $r$ being the highest for the instantaneous cross-shore $u(r=0.54)$ and the 2-min averaged alongshore $\bar{v}(r=0.76)$ components. The mean relative errors (MRE) are particularly high for $u$ and $\bar{u}$, however as per the previous remarks a direct comparison with the ADV is less relevant for these components. The limited accuracy of the OF estimation, in the given conditions, also contributes to such 

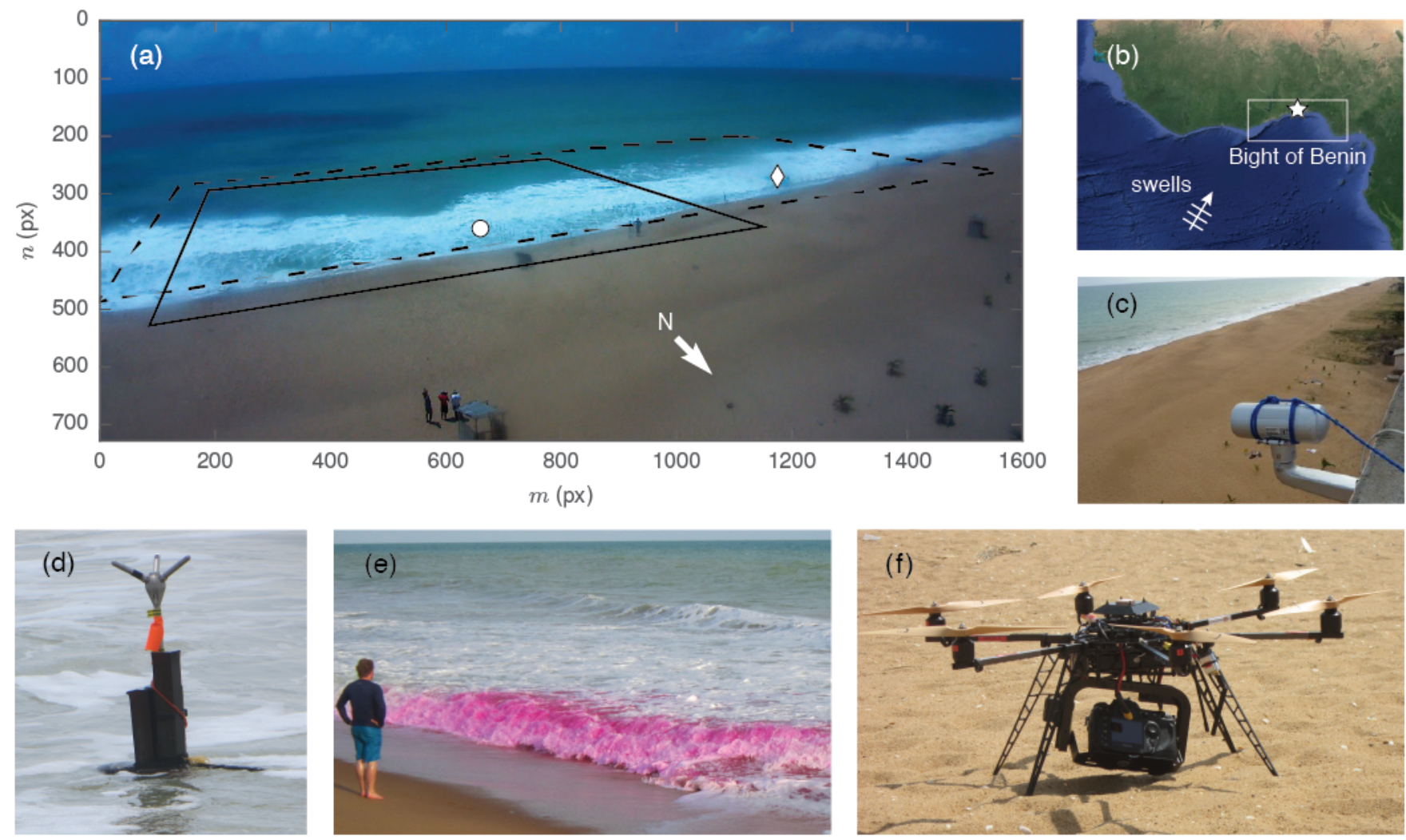

Fig. 1. Field experiment. View of the the beach of Grand Popo, Benin (a) in the Gulf of Guinea, West Africa (b), as taken by the camera mounted on a semaphore of the Navy (c). The circle and diamond markers in (a) represent the location of the ADV (d) and the dye release (e), respectively. Black polygons in (a) delimit the regions of interest for the surface current estimation: time-series comparison with the ADV $(60 \times 60 \mathrm{~m}$, continuous line) and monitoring of a "flash rip" event $(120 \times 60 \mathrm{~m}$, dashed line). The UAV hexacopter, also used to monitor the flash rip, is shown in (f). Image (b) Landsat/Copernicus; US Dept of State Geographer; Data SIO, NOAA, U.S. Navy, NGA, GEBCO; (C2016 Google.

high relative errors. If displacements were measured in integer values on the image grid and, assuming a perfect model, ideal data and conditions, the systematic error would be $\pm 0.5 \mathrm{px}$. For the OF measures from images at $\approx 2 \mathrm{~Hz}$ and $0.1 \mathrm{~m} / \mathrm{px}$, this corresponds to $\pm 0.5 \delta_{x} / \delta_{t}= \pm 0.1 \mathrm{~m} / \mathrm{s}$. With instantaneous alongshore velocities on the order of $0.5 \mathrm{~m} / \mathrm{s}$, this gives an already significant relative error of 0.2. As discussed further below, the conditions are here fairly difficult and image data is far from ideal, which explains even larger errors. Nonetheless, it can be noted that with a root mean squared error (RMSE) of $0.12 \mathrm{~m} / \mathrm{s}$, the 2 -min averaged alongshore component $\bar{v}$ is very close to the theoretical $0.1 \mathrm{~m} / \mathrm{s}$ bound.

Power spectral densities (PSD) are estimated from the 4.5 hour time-series at $0.5 \mathrm{~Hz}$ using Welch's periodogram (overlapping segments of $15 \mathrm{~min}$ ), they are presented Fig. 5 (top). Spectra are in good agreement for both velocity components, although the OF $u$ peak appears broadened toward the high frequencies. For the main peak, this can be explained by the Doppler shift in the apparent frequencies seen by the instruments. As already observed in Fig. 3 (top), the mean crossshore velocity varies significantly between OF observations at the surface and ADV measures down below. Consequently, the apparent frequencies are Doppler-shifted differently on the two instruments. For each frequency $f$ and cross-shore velocity observations $u$ by a given instrument, the corrected frequency can be estimated to first order by $f_{0}=\frac{c}{c+\bar{u}} f$, where the average $\bar{u}$ is here taken over the entire time-series for this instrument, $c=\sqrt{g h}$ and the water depth $h=1 \mathrm{~m}$. Corrected spectra are shown in Fig. 5 (bottom). The peak in the cross-shore spectra now line up for both OF and ADV at a frequency of $0.08 \mathrm{~Hz}$ (period of $12.5 \mathrm{~s}$ ) corresponding to the passing waves. This suggests that the surface mean cross-shore velocities seen by OF and presented Fig. 3 (top) are correct. However, the residual shift at highest frequencies remain unexplained.

TABLE I

STATISTICS COMPUTED FOR THE VARIOUS VELOCITY COMPONENTS: CORRELATION COEFFICIENT $(r)$, MEAN RELATIVE ERROR (MRE) AND ROOT MEAN SQUARE ERROR (RMSE).

\begin{tabular}{c|c|c|c|c} 
component & \# points & $r\left(r^{2}\right)$ & MRE & RMSE $(\mathrm{m} / \mathrm{s})$ \\
\hline$u$ & 8130 & $0.54(0.29)$ & 1.20 & 0.65 \\
\hline$v$ & 8130 & $0.22(0.05)$ & 0.58 & 0.58 \\
\hline $\bar{u}$ & 135 & $0.36(0.13)$ & 4.13 & 0.22 \\
\hline $\bar{v}$ & 135 & $0.76(0.58)$ & 0.21 & 0.12
\end{tabular}

\section{Flash rip: comparison with dye release}

1) From shore-based camera: An important potential of using the OF method in the nearshore is the monitoring of transient circulation. In this experiment, a dye release is first 
(a)

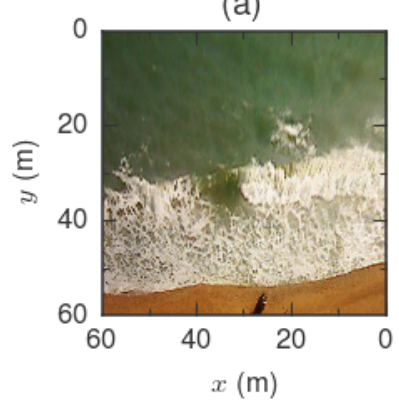

(c)

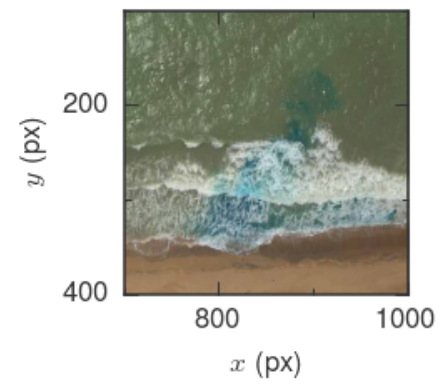

Fig. 2. Before (color, left) and after pre-processing (grayscale, right) of input frames for the shore (top) and UAV (bottom) data. Shore video data is rectified (a), UAV data is motion-compensated (c). The median filtering (b), (d) limits the influence of wave rollers. $5 \mathrm{~m}$ and $35 \mathrm{px}$ windows were used for the shore and UAV data, resp. Note how the dye in (c) is not visible in (d).

taken out of the surf zone and dispersed by a flash rip filament, then drifts over hundreds of meter following the alongshore current. Here, the motion estimation was performed on a wider $120 \times 60 \mathrm{~m}$ field (Fig. 1 a, dashed black line) at $0.2 \mathrm{~m} / \mathrm{px}$ resolution. Surface current fields of Fig. 6, superimposed on input images, show steps of the rip generation, development and drifting: first, (a) a large individual wave breaking occurs with strong onshore-oriented current, generating several seconds later (b) a current oriented offshore $(x=40 \mathrm{~m})$ which (c) intensifies, drifts $(x=70 \mathrm{~m})$ and (d) impacts back on breaking pattern and vanishes slowly. The signature of the drifting dye, advected by the rip, is barely visible as a faint blue streak, starting after the large breaking event. The offshore-oriented current signature of the rip can then be noticed in the estimated vector field as it drifts. Throughout the rip inception and development duration, there is a good spatio-temporal coherence between the breaking and current patterns. A video illustrating the estimated surface current is provided as additional material.

2) From UAV: The dye release was also monitored by UAV. Fig. 7 presents a sequence of four images (after UAV motion compensation, before any filtering, akin to Fig. 2 2 c) featuring the inception and development of the rip into a narrow filament [28]. Without proper image rectification for this data set, the conversion from observed displacement to instantaneous velocity (1) is not possible. Instead, virtual passive tracers enable to assess the match between the estimated flow and the actual one. This approach can be interpreted as a qualitative lagrangian error.
The virtual drifter experiment is handled as follows. First, estimated velocity fields are averaged in time over a $10 \mathrm{~s}$ centered window in order to attenuate the influence of rollers. Second, 100 drifters are randomly generated in a $40 \times 150 \mathrm{px}$ rectangular box (the "seeding box") centered at $(m, n)=$ $(980,275)$ px. The seeding box effectively extends across the surf zone and covers the dye release location. Then, the drifters are advected by the time-averaged estimated flow. At every time-step, the seeding box is translated horizontally (alongshore) by the median of the horizontal displacement of the 100 drifters. Drifters ending up too far off the surf zone $(n<150 \mathrm{px})$ or on the beach $(n>370 \mathrm{px})$ are simply re-generated within the moving seeding box. In this timeaveraged sequence of $280 \mathrm{~s}$, the average tracer lifetime is $59 \mathrm{~s}$ with a standard deviation of $49 \mathrm{~s}$.

The passive drifters are superimposed on the images of Fig.7 They are caught offshore by the rip and grouped into the filament that lays out of the surf zone, offshore of the peak of longshore current [4]. Their location closely follows that of the dye throughout the entire sequence, suggesting a good match between OF estimations and the actual surface flow. Two videos of the full sequence are available as additional material: instantaneous and 10-s averaged velocities (same as Fig. 7).

\section{DISCUSSION}

\section{A. Data resolution and quality}

It must be mentioned first that the Grand Popo 2014 field campaign (Fig. 1) was not designed with the OF application in mind. Shore images were acquired at $2 \mathrm{~Hz}$. At such temporal resolution, wave rollers result in important visual deformations of the foam pattern, which perturb the OF estimation. These deformations are amplified by the low elevation angle of the shore camera which captures some of the rollers' vertical motion. While the rectification and the high-pass median filter help reducing the influence of the rollers, a slightly higher and more stable acquisition frequency should help improving significantly the quality of estimates. However, with a computation time currently on the order of $2 \mathrm{~s}$ per frame pair, the algorithm is presently unable to keep up with the real-time. One possibility, often seen in PIV, consists in increasing the camera framerate while performing the estimation at a lower frequency (e.g. to estimate every $2 \mathrm{~s}$ from a pair of frames separated by $\delta_{t}=0.25 \mathrm{~s}$ ). Another difficulty comes here from the pixel footprint: with a value of $0.25 \mathrm{~m}$ in the vertical image direction at the ADV location, it is greater than the $0.1 \mathrm{~m} / \mathrm{px}$ rectified grid resolution. As such, rectified images show limited fine scale details, which impacts the estimation precision. There is much room for improvement however, as the camera operated only slightly above $1 \mathrm{Mpx}$ during this experiment. The "optimal" temporal and spatial resolutions are connected to the range of velocities to be observed as well as to hardware limitations. This choice is here complicated by the huge discrepancy between the large-scale, rapid rollers and the small-scale, slow foam features.

On another note, the shore videos often presented artifacts as a results of droplets or sand on the camera housing, leading 

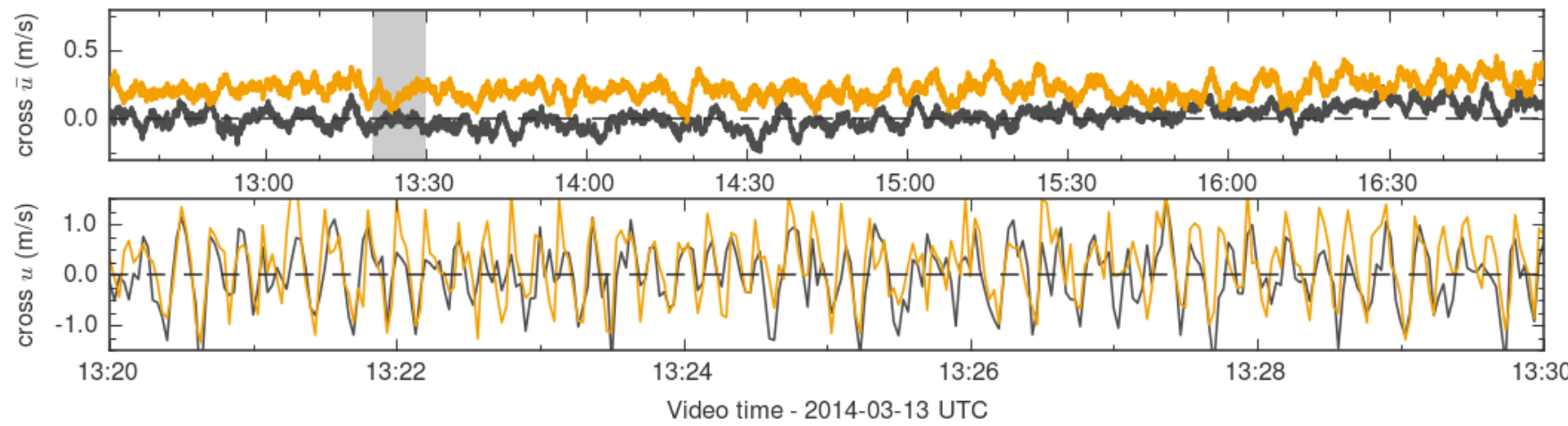

Fig. 3. Time-series of current measured by the ADV (dark gray) and from OF (orange), on March 132014 at Grand Popo, Benin in the cross-shore direction The upper panel exhibits the slow variations over $4.5 \mathrm{~h}$ through the 2-min rolling mean. The lower panel focuses on a 10 min window (shown as a light gray area above) and presents the instantaneous measures resampled at $0.5 \mathrm{~Hz}$.

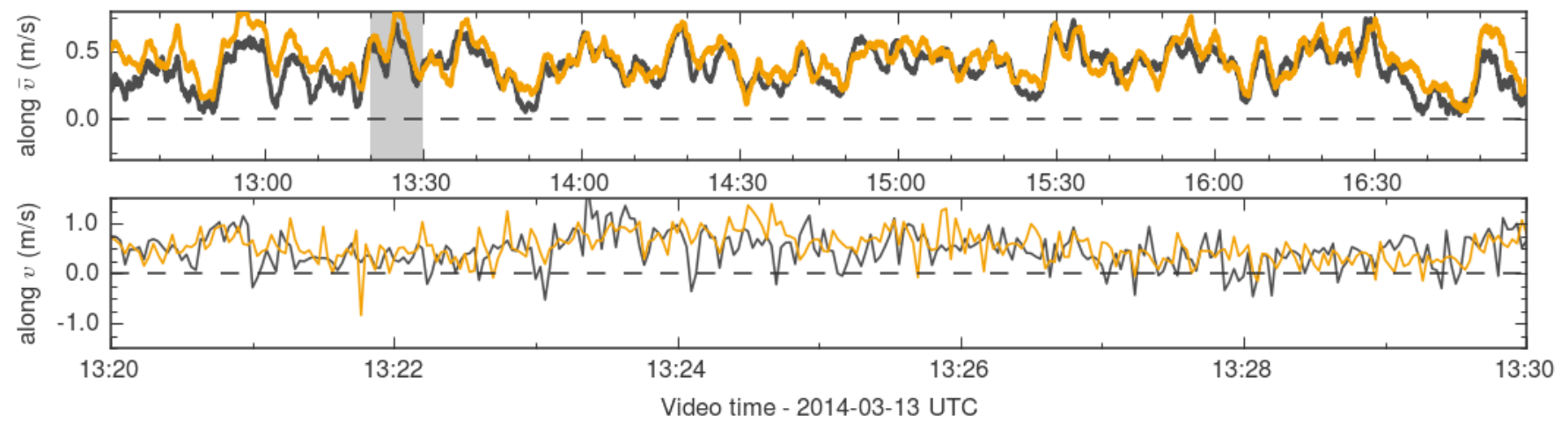

Fig. 4. Time-series of current measured by the ADV (dark gray) and from OF (orange), on March 132014 at Grand Popo, Benin in the alongshore direction. The upper panel exhibits the slow variations over $4.5 \mathrm{~h}$ through the 2 -min rolling mean. The lower panel focuses on a 10 min window (shown as a light gray area above) and presents the instantaneous measures resampled at $0.5 \mathrm{~Hz}$.

to blurry regions in the rectified images. Overall, this data set proved fairly challenging for the OF.

\section{B. Typhoon (OF) and cross-correlations}

Comparing estimates given by these two methods is out of the scope of this paper and left for future work. Nevertheless, a few words can be said about the benefits and disadvantages of both approaches. CC-based methods are usually more robust to large displacements, which would make them suitable to handle the wave rollers. And, by their design, they are particularly useful when a few vectors only are needed (e.g., to monitor currents at a specific location in the camera field of view, akin to a virtual probe). OF approaches, on the opposite, are designed to provide entire fields. Typhoon has also demonstrated its ability to estimate finer structures than CC on PIV [15] and lidar [11] data. Thus, without considering their respective accuracy and precision, the two methods can be seen as complementary: CC for isolated observations of rather large displacements, OF for entire fields of finer motions.

\section{CONCLUSIONS}

We have presented a methodology based on the "Typhoon" implementation of a wavelet-based optical flow (OF) algorithm to estimate nearshore surface currents from image sequences. This approach computes entire 2D 2-component fields from the apparent motion of foam pattern in the surf zone. A 2D high-pass median filter proved efficient at isolating these fine-scale foam patterns from large-scale structures such as propagating wave rollers. The shore camera data was fairly challenging for the algorithm with its fluctuating acquisition time-step, perspective distortions, important deformations, vertical wave motion as well as artifacts due to the environment (salt, sand). Furthermore the spatial and temporal resolutions of the image sequence were low considering the range of velocities to be measured, resulting in somewhat large relative errors. Comparison of OF measures to that of an ADV were limited by their different location on the vertical profile: surface for OF versus 1/4 depth for the ADV. Nevertheless, the OF estimates appear to capture the wave-by-wave current in the surf zone, especially in the cross-shore direction, and the slower variations of the alongshore component are in good agreement. A spectral analysis leans toward validating the slow variations of the cross-shore component. The method was then successfully applied to the detection and monitoring of a flash rip event from shore-based camera and UAV images.

Our study highlights the potential of OF methods such as Typhoon in the nearshore where the rapid development of 


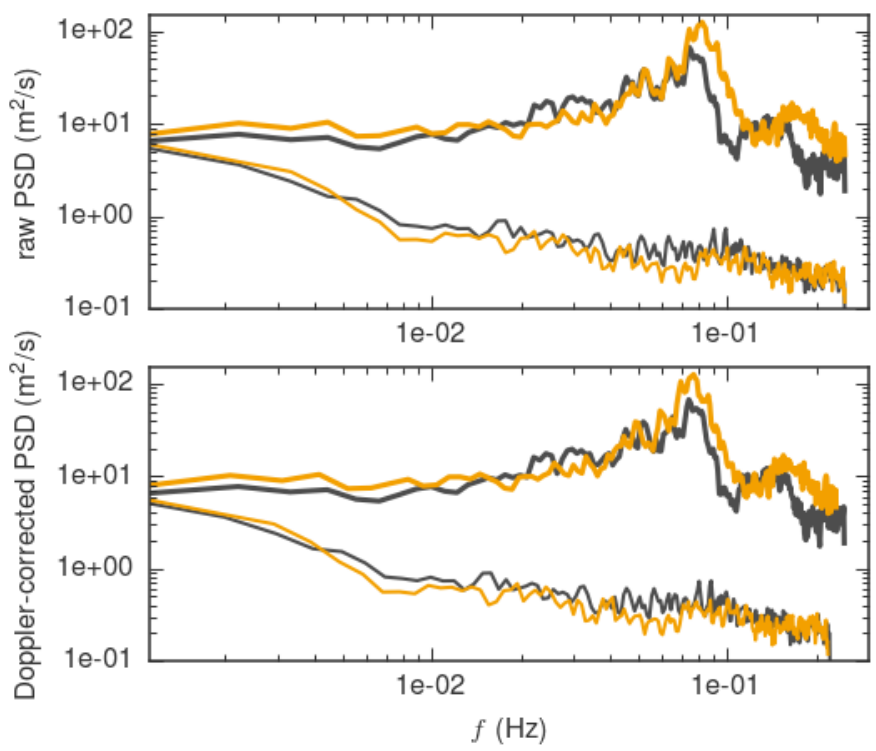

Fig. 5. PSD of cross-shore $u$ (thick lines) and alongshore $v$ (thin lines) velocity components for the ADV (dark gray) and OF (orange). Cross-shore spectra are offset by one order of magnitude for better readability. Upper panel shows raw spectra while those in the lower panel have been corrected for the Doppler shift.

webcams and drones offers many applications for swimming and surfing safety, engineering and naval security and research purpose, by providing quantitative information at a reasonable instrumental and computational cost. This bridges the gap of nearshore studies between isolated Eulerian measurements and large-scale measurements, through Lagrangian temporally sparse drifters [29]) or dye methods [30]. In addition to previous 1D methods computing the alongshore current from time-stacks or spatio-temporal images, based on correlation [3] or Radon transform [4], this algorithm provides directly an instant 2D field, which enables to monitor both the average and transient circulation, such as flash rips, for which the location of occurrence is random and instrumentation is extremely difficult. Overall, these results promote the use of such a method for data assimilation, such as in [14] where surface current are provided by radar, together with wave energy fluxes (dissipation and celerity, beach Wizard, [13]), in particular with 3D numerical models (e.g., Delft3D, CROCO [31]) to account for the vertical profile of currents.

\section{ACKNOWLEDGMENTS}

We are greatly indebted to the naval services of Benin at Grand Popo for their logistic support during the field experiment and for allowing the installation of the permanent video system on the semaphore. We also gratefully thank Dr. S. Mayor from the California State University, Chico for helping us with computational resources. Finally, we thank the anonymous reviewers for their constructive comments which helped improving this paper.

\section{REFERENCES}

[1] D. Haller, M. Honegger and P. Catalan, "Rip current observations via marine radar," J. Waterw. Port Coast. Oc. Eng., vol. 140(2), pp. 115-124, 2014.
[2] R. Holman and M. Haller, "Remote sensing of the nearshore," Annu. Rev. Mar. Sci., vol. 113, pp. 5-95, 2013.

[3] C. Chickadel, R. Holman, and Freilich, "An optical technique for the measurement of longshore currents," J. Geophys. Res.-Oceans, vol. 108(C11), pp. 73-82, 2003.

[4] R. Almar, S. Larnier, B. Castelle, T. Scott, F. Floc'h, J.-P. Lefebvre, N. Senechal, G.-H. Houngue, R. Laibi, and G. Detandt, "On the use of the Radon transform to estimate longshore currents from video imagery," Coastal Eng., vol. 114, pp. 301-308, 2016.

[5] K. Holland, J. Puleo, and T. Kooney, "Quantification of swash flows using video-based particle image velocimetry," Coastal Eng., vol. 44(2), pp. 65-77, 2001.

[6] J. Puleo, G. Farquharson, S. Frasier, and K. Holland, "Comparison of optical and radar measurements of surf and swash zone velocity fields," J. Geophysical Res., vol. 108, p. C3 3100, 2003.

[7] A. B. Kennedy and D. Thomas, "Drifter measurements in a laboratory rip current," J. Geophys. Res.-Oceans, vol. 109, no. C8, 2004.

[8] D. Perkovic, S. Frasier, and T. Lippmann, "Longshore surface currents measured by Doppler radar and video PIV techniques," IEEE Trans. Geosci. Remote Sens., vol. 47(8), pp. 2787-2800, 2008.

[9] D. Cox and S. Anderson, "Statistics of intermittent surf zone turbulence and observations of large eddies using PIV," Coastal Eng., vol. 43, pp. 121-131, 2001

[10] O. Kimmoun and H. Branger, "A particle images velocimetry investigation on laboratory surf-zone breaking waves over a sloping beach," $J$. Fluid Mech., vol. 588, pp. 353-397, 2007.

[11] P. Dérian, C. F. Mauzey, and S. D. Mayor, "Wavelet-based optical flow for two-component wind field estimation from single aerosol lidar data," J. Atmos. Ocean. Technol., vol. 32, no. 10, pp. 1759-1778, 2015.

[12] R. Holman, K. Holland, D. Lalejini, and S. Spansel, "Surf zone characterization from unmanned aerial vehicle imagery," Ocean Dynam., vol. 61(11), pp. 1927-1935, 2011.

[13] A. van Dongeren, N. Plant, A. Cohen, D. Roelvink, M. Haller, and P. Catalán, "Beach wizard: Nearshore bathymetry estimation through assimilation of model computations and remote observations," Coastal Eng., vol. 55(12), pp. 1016-1027, 2008.

[14] G. Wilson, H. Özkan-Haller, R. Holman, M. Haller, D. Honegger, and C. Chickadel, "Surf zone bathymetry and circulation predictions via data assimilation of remote sensing observations," J. Geophys. Res.-Oceans, vol. 119(3), pp. 1993-2016, 2014.

[15] P. Dérian, P. Héas, C. Herzet, and E. Mémin, "Wavelets and optical flow motion estimation," Num. Math. Theor. Meth. Appl., vol. 6, no. 1, pp. 116-137, February 2013.

[16] S. Kadri-Harouna, P. Dérian, P. Héas, and E. Mémin, "Divergence-free wavelets and high order regularization," Int. J. Computer Vision, vol. 103, no. 1, pp. 80-99, 2013.

[17] B. K. Horn and B. G. Schunck, "Determining optical flow," Artif. Intell., vol. 17, pp. 185-203, 1981

[18] S. Mallat, A wavelet tour of signal processing: the sparse way. Academic press, 2008.

[19] D. Dee, S. Uppala, A. Simmons, P. Berrisford, P. Poli, S. Kobayashi, U. Andrae, M. Balmaseda, G. Balsamo, P. Bauer et al., "The ERAinterim reanalysis: Configuration and performance of the data assimilation system," Quart. J. Roy. Meteor. Soc., vol. 137, no. 656, pp. 553-597, 2011.

[20] R. Almar, E. Kestenare, J. Reyns, J. Jouanno, E. Anthony, R. Laibi, M. Hemer, Y. Du Penhoat, and R. Ranasinghe, "Response of the Gulf of Guinea coastline to anthropogenic and natural forcing, part1: Wave climate variability and impacts on longshore sediment transport," Cont. Shelf Res., vol. 110, pp. 48-59, 2015.

[21] E. Anthony and A. Blivi, "Morphosedimentary evolution of a deltasourced, drift-aligned sand barrier-lagoon complex, western Bight of Benin.” Mar. Geol., vol. 158, pp. 161-176, 1999.

[22] A. Blivi, E. Anthony, and L.-M. Oyédé, "Sand barrier development in the Bight of Benin, West Africa," Ocean Coast Manage., vol. 45, pp. 185-200, 2002.

[23] B. Castelle, Y. du Penhoat, R. Almar, E. Anthony, J. Lefebvre, R. Laibi, R. Chuchla, M. Dorel, and N. Senechal, "Flash rip dynamics on a highenergy low-tide-terraced beach (Grand Popo, Benin, West Africa)," J. Coastal Res., vol. SI 70, pp. 633-638, 2014.

[24] R. Almar, N. Du Penhoat, Y.and Honkonnou, B. Castelle, R. Laibi, E. Anthony, S. N., G. Degbe, R. Chuchla, Z. Sohou, and M. Dorel, "The Grand Popo experiment, Benin," J. Coastal Res., vol. SI 70, pp. 651-656, 2014.

[25] K. Holland, R. Holman, T. Lippmann, J. Stanley, and N. Plant, "Practical use of video imagery in nearshore oceanographic field studies," IEEE J. Ocean. Eng., vol. 22(1), pp. 81-82, 1997. 
(a) $11: 17: 15$ UTC

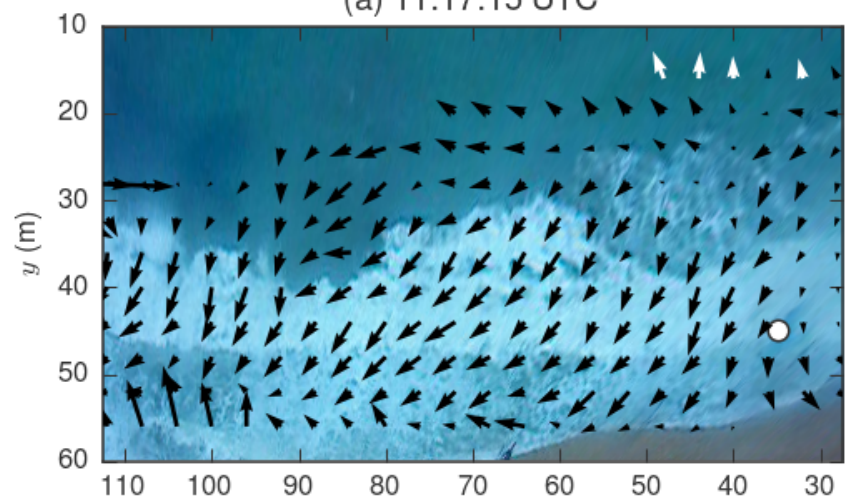

(c) 11:19:05 UTC

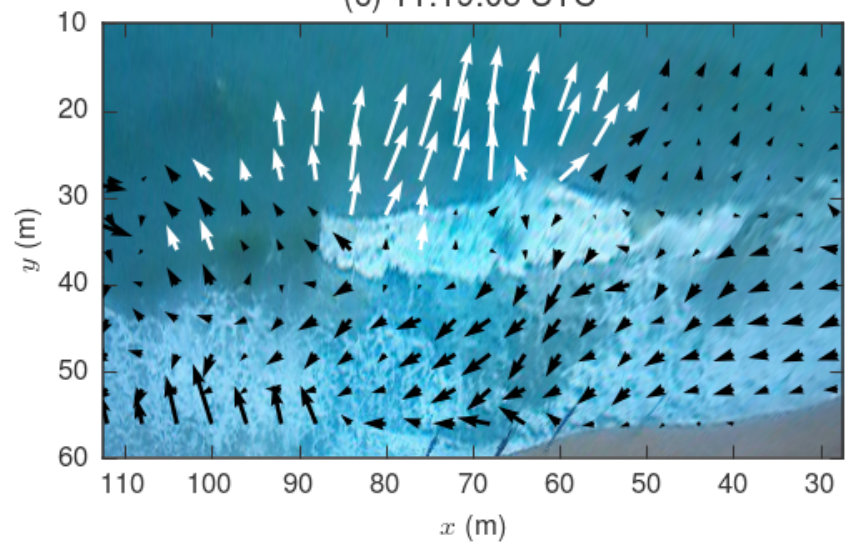

(b) 11:17:55 UTC

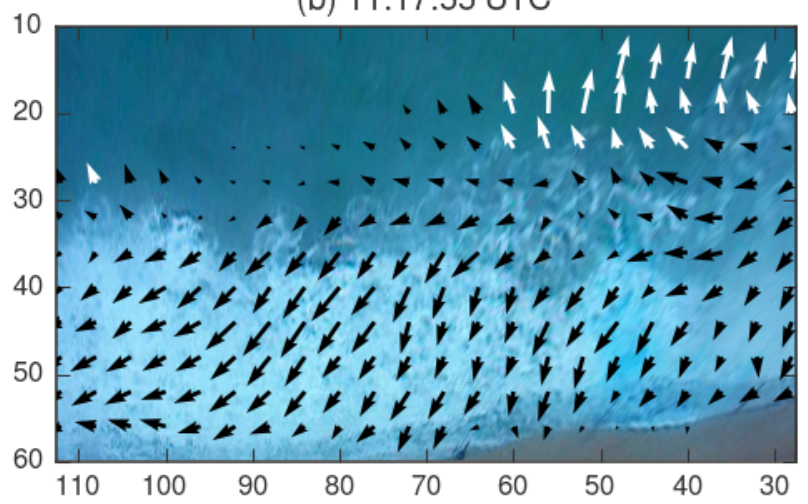

(d) 11:19:55 UTC

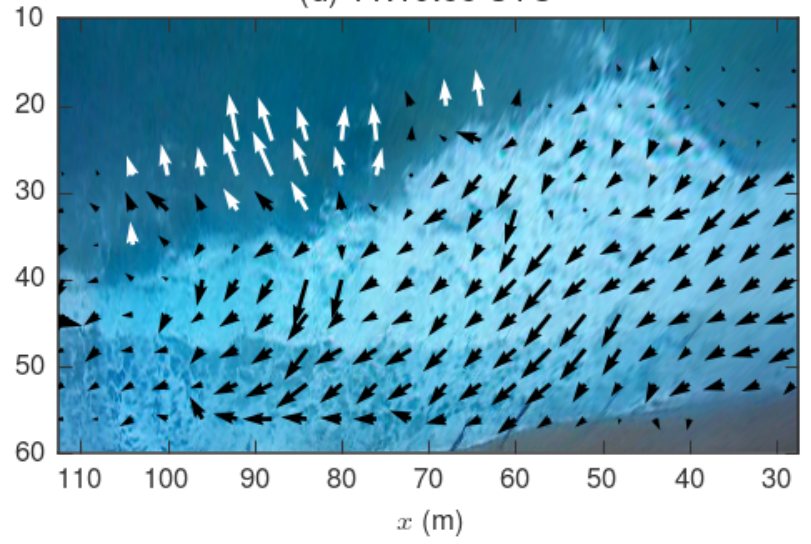

Fig. 6. Flash rip occurring on March 122014 11:17 UTC at Grand Popo. The white round marker in (a) denotes the dye release location. (a)-(d) Sequence of rectified shore images with estimated surface current superimposed (arrows). White vectors have a cross-shore velocity component $>0.75 \mathrm{~m} / \mathrm{s}$, they correspond to the flash rip. Vector fields were time-averaged over a 10-s centered box window; they are presented here sub-sampled by a factor of 20 in every spatial direction to enhance visualization.

[26] J. Heikkila and O. Silven, "A four-step camera calibration procedure with implicit image correction," Computer Vision and Pattern Recognition. In Proceedings of the IEEE Computer Society Conference, pp. 1106$11012,1997$.

[27] S. Larnier, R. Almar, R. Cienfuegos, and A. Lejay, "On the use of the Radon transform to estimate longshore currents from video imagery," $J$. Coastal Res., vol. SI 70, pp. 23-28, 2014.

[28] P. Marchesiello, R. Almar, R. Benshila, S. Larnier, B. Castelle, and J. McWilliams, "On eddy-mixed longshore currents: video observation and 3d modeling off Grand Popo beach, Benin," J. Coastal Res., vol. SI 75, pp. 408-412, 2016.

[29] J. MacMahan, J. Brown, and E. Thornton, "Low-cost hand-held global positioning system for measuring surf-zone currents," J. Coastal Res., vol. 25(3), pp. 744-754, 2009.

[30] K. Hally-Rosendahl, F. Feddersen, D. Clark, and R. Guza, "Surfzone to inner-shelf exchange estimated from dye tracer balances," J. Geophys. Res.-Oceans, vol. 120, p. 10.1002/2015JC01084, 2015.

[31] R. Benshila, P. Almeida, R. Almar, and P. Marchesiello, "Hydrodynamic response to a tropical storm: a case study," Journées de Génie Côtier Génie Civil, Paralia, vol. 10.5150/jngcgc.2016.003, pp. 19-28, 2016.

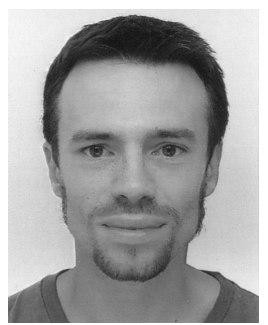

Pierre Dérian received the Engineering degree in Applied Mathematics from the National Institute for Applied Sciences (Insa) in Toulouse, France in 2009 and a Ph.D. in Applied Mathematics at MATISSE, University of Rennes I, France in 2012. He is currently a postdoc researcher in the Fluminance team of the French National Institute for computer science and applied mathematics (Inria) in Rennes, France. His research focuses on the development and applications of solutions for the remote measurement of fluid motion from image data of various nature, and, more recently, large-scale oceanic models built from the "location uncertainty" paradigm.

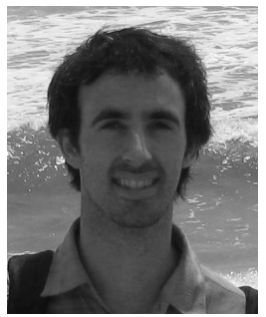

Rafael Almar received the M.Sc. degree in Atmosphere, Ocean and Climate Sciences from Toulouse University, France in 2006 and a Ph.D. in Coastal Oceanography at EPOC from the University of Bordeaux in 2009. He is currently a researcher at the Institute for Research and Development (IRD) at LEGOS in Toulouse, France. His current research interests are the development of video imagery techniques (from shore-based video, UAV and satellite), the interaction between morphology and waves in the surf and swash zones, and at broader scale, the impact of events to the downscaling of regional climate driving coastal evolution. 
(a) frame \#005

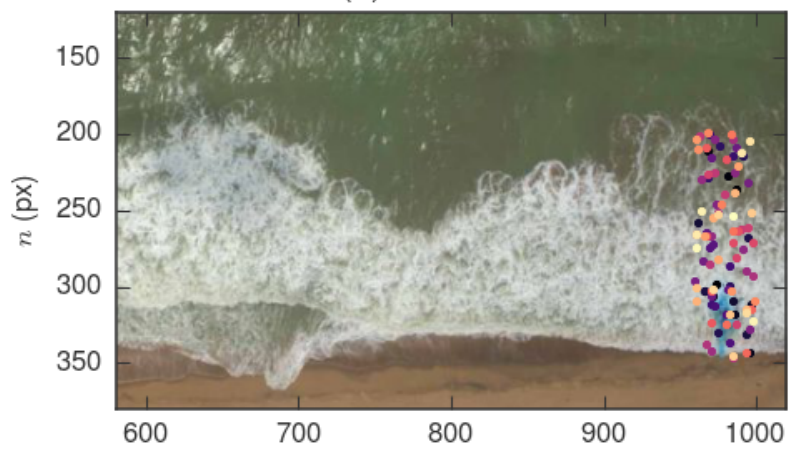

(c) frame \#124

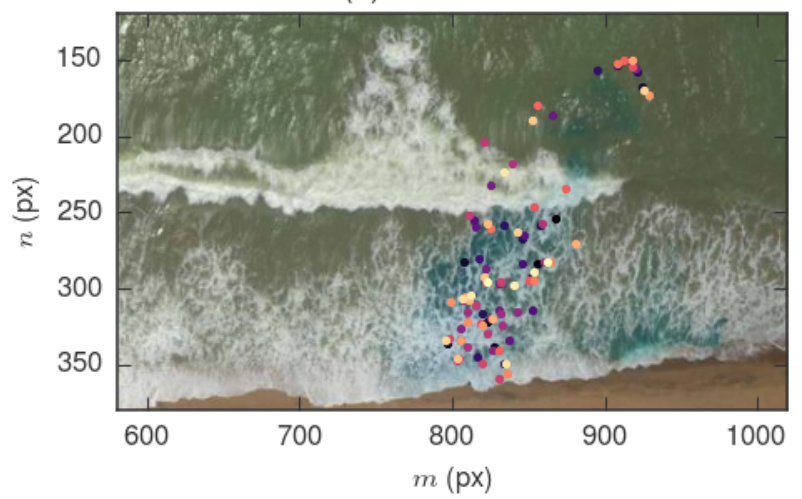

(b) frame \#050

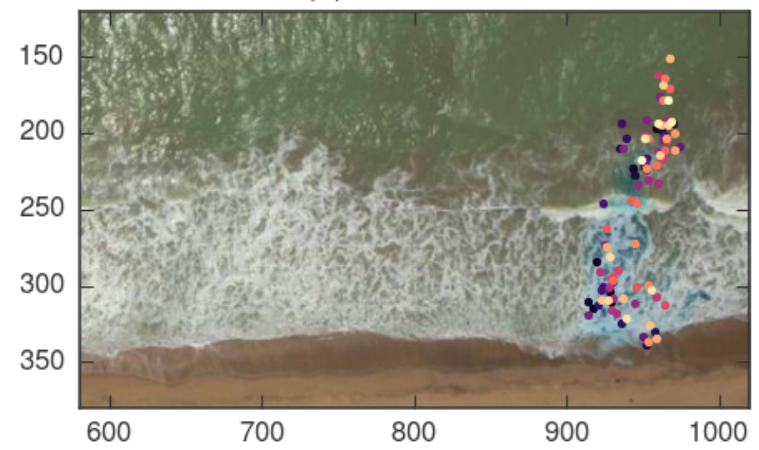

(d) frame \#240

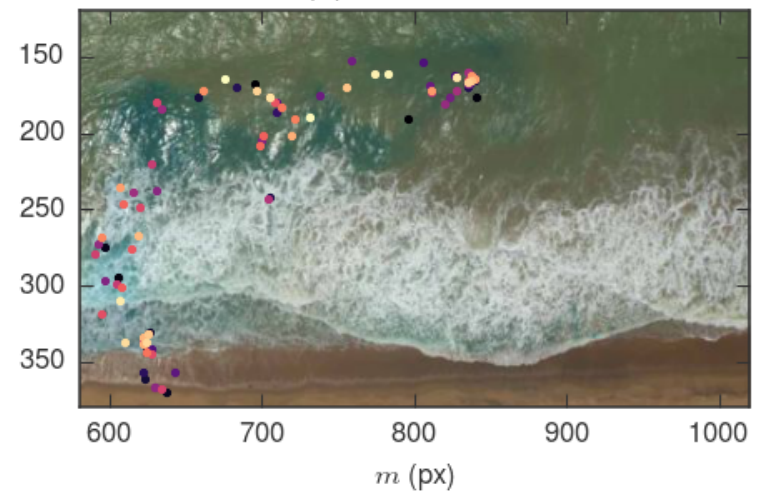

Fig. 7. Virtual drifters advected by the flow estimated from UAV images. The velocity fields were averaged over a 10-s centered window. Drifters are initialized in the "seeding box" in (a) and closely follow the dye in (b)-(d) as it progressively forms a filament over the course of approximatively 4 min. 